\title{
Design and Development of a Portable Metal Chip Baler using A System Design Approach
}

\author{
Mohd Fahrul Hassan 1,*, Mohd Faiz Afham ${ }^{1}$, Ahmad Mubarak Tajul Arifin ${ }^{1}$, Al Emran \\ Ismail $^{1}$, Mohd Rasidi Ibrahim ${ }^{1}$, Mohammad Zulafif Rahim ${ }^{1}$, Md Fauzi Ahmad ${ }^{2}$ \\ ${ }^{1}$ Faculty of Mechanical and Manufacturing Engineering, Universiti Tun Hussein Onn Malaysia, \\ 86400 Parit Raja, Batu Pahat, Johor, Malaysia \\ ${ }^{2}$ Faculty of Technology Management, Universiti Tun Hussein Onn Malaysia, 86400 Parit Raja, Batu \\ Pahat, Johor, Malaysia
}

\begin{abstract}
A large amount of metal chips at workplace will result in untidy and unsafe condition thus measurements of safety are needed in some industries, where the metal chips will be collected and put into a container until the volume is sufficient to be recycled. Due to that reason, the metal chips require a lot of spaces for storage before going to recycle. In this study, a portable metal chip baler as a device for compacting those metal chips is presented based on a system approach of engineering design. Basically, the system design evolves through four phases of development that are started from conceptual design, preliminary system design, detail design and development to system test and evaluation. The portable metal chip baler uses current technology such as pneumatic cylinder to compress the metal chips so that the system capable to operate efficiently. The output from this system is the metal chips are compacted into a block shape and a working prototype was developed to prove the concept of the system. As a summary, the conceptual design of portable metal chip baler was proven and was presented using the philosophy of the systems design approach. This tool may assists workers especially in the Small-Medium Enterprise (SME) manufacturing industries, school or universities' workshops for managing metal chips easily and systematically.
\end{abstract}

\section{Introduction}

Waste is a type of substance that are unwanted or unused. The examples of waste are municipal waste (household trash), hazardous waste, wastewater (sewage), radioactive waste and others [1]. This waste can cause negative effect to the environment, social and economy. Exposure to hazardous wastes, particularly when they are burned, can cause various other diseases including cancers. Toxic waste materials can contaminate water, soil, and air which causes more problems for humans, other species, and ecosystems [2]. The issue of metal waste associated with environmental management has been faced by manufacturing industry sectors, and immediately has to complement innovating technologies to productive processes in order to reach sustainability [3].

In this study, the waste that involved are metal waste that are produced from machining process in industry. Usually the process that involves in machining process of metal are

\footnotetext{
${ }^{1}$ Corresponding author: fahrul@uthm.edu.my
} 
drilling, milling, lathe and others. The main purpose of these processes are mainly to achieve a single objective that is to obtain a desired geometry on the metal workpiece. These processes produce metal waste by removing the unwanted metal on the workpiece and the type of metal waste that are produced are metal chips. Some industries have taken a good initiative to overcome those issues where it gives benefit to the industries as well in terms of end-of-life profit by recycling the metal chips [4]. In order to recycle the metal chips, a larger space is needed to store these metal chips before the metal chips can be recycled. Fig. 1 shows the problem that has been faced by the manufacturing industries.

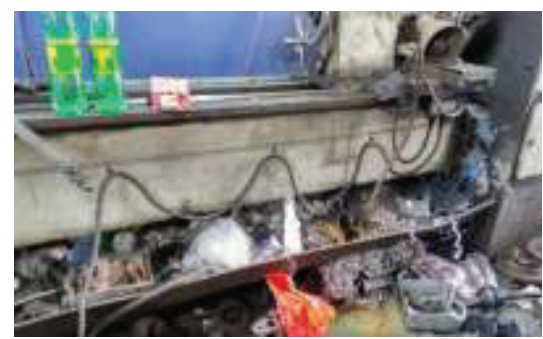

Fig. 1. Metal Chip formation from machining process.

Due to this problem, this paper presents a portable metal chip baler as a device for compacting those metal chips using a system design approach. The system design is used in this study to assist the design and development process of the portable metal chip baler systematically. The detail of the system design process is described in the next section, continued with the design and development of the portable metal chip baler and end up with the conclusion section.

\section{Methodology}

\subsection{A System Design Process}

The system design has been introduced with in great detail ever since around 1940 [5]. The purpose of this scientific approach is to assist in the planning, design, development, manufacture and evaluation of engineering systems. In this section, a part of the system design process from Misra [5] as a reference of this study has been described, as follows:

\subsubsection{Phases of System Design}

Basically, the system design evolves through several phases of development that started from (1) Conceptual Design, (2) Preliminary System Design, (3) Detail Design and Development to (4) System Test and Evaluation.

Phase 1: Conceptual Design. Conceptual design is the basis on which the lifecycle phases of the remaining stages of system design. Conceptual design changes from:

- Functional definition of the system based on identified needs of the system and the customer requirements.

- Establishment of design criteria.

Phase 2: Preliminary System Design. The system level requirements obtained from the conceptual design phase will be translated into subsystem level requirements in this phase. 
It also extends functional analysis and requirements allocation from the baseline, to the depth that is needed to identify specific requirements for specific components and other related resources. These resources may be in the form of software, hardware, people, data, facilities, or their combinations. A review on system design is undertaken to ensure that the needs are achieved and the results of the functional analysis and allocation process, the design approach selected, the trade-off studies, etc., are reviewed for compliance with the initially set requirements. All information are documented, and the necessary corrective measures as considered appropriate are initiated. This phase provides results that are supporting detail design and development.

Phase 3: Detail Design and Development. In this phase, the design requirements are derived from the system specifications from the previous phase. The specifications include appropriate design dependent parameters, technical performance measures and associated design to criteria for characteristics that must be incorporated into the system design, subsystems and components. Design requirements for each system element are specified through the allocation process and the identification of detailed performance and effectiveness parameters for each element in the functional analysis. Detail design documentation is an essential part of detail design phase and generates a database for the purpose of information processing, storage and retrieval so that it can be used during the testing and is also available for future designs. At this stage, the design system may be evaluated through the fabrication of a prototype model or using a physical working model. Detail design review is undertaken generally after the detail design has been completed, but before the release of firm design data to initiate production and/or fabrication.

Phase 4: System Test and Evaluation. The idea of evaluation is that the functions that the system must perform to satisfy a specific user need should be assessed along with the expectations in terms of costs, time, effectiveness, frequency and any other factors. However, the functional requirements that start at the system level are expected to determine the characteristics that should be incorporated within the system design and its subsystems and components. System evaluation is a continuous process and is undertaken starting with the conceptual design, and extends to the operational use and support phase, and concludes only when the system is retired. The objective of system evaluation is to determine (through a combination of prediction, analysis and measurement activities) true system characteristics and to ensure that the system successfully fulfils its intended purpose or mission.

In the meantime, testing is done at each design stage to ensure that the design is evolving in the intended direction and goal. For example, feasibility testing is done by the designer to prove the design concept and to choose the most promising concept from several possible design concepts. Evaluation testing is done to test early hardware in the operating and environmental conditions for which it was designed. Test procedures and test results are recorded.

\section{The System Design Process for a Portable Metal Chip Baler}

\subsection{Conceptual Design}

The solution of a problem is the main aspect of designing. The purpose of design is to make something new that is something that is not existed yet or modifying to an existing product to fulfil customers' needs and to improve the design to ease human daily task. 
Function analysis is a method used for analysing a function structure which is an abstract model of a new product, without material features such as shape, dimensions and materials of the parts. It describes the functions of the product and its parts and indicates the mutual relations which underlays ideas that a function structure may be built up to from a number of functions. Fig. 2 shows the black box model for portable metal chip baler. The input of the black box for the portable metal chip baler is electricity, air, signal and also the metal waste. These inputs are the necessary items to perform the design objective. Meanwhile, the output of the black box is compacted metal chip.

Function structure analysis explains about the process that occurs starting from the supplied input until an output is obtained. In the portable metal chip baler system, there are several processes have been carried out before the complete product or processed product is obtained. For initial process, the electricity is used to run the compressor so air can be sucked and compressed into a storage air tank to obtain high air pressure. When high compressed air are obtained, the metal chip will be poured into the product design feed. Then it is fill up the compaction chamber that are design for the metal chip. Next process is the compaction process that occurs after the metal chip fills up the compaction chamber. The high air pressure are then released into the pneumatic cylinder and pushed the metal plate thus compacting the metal chip and this process are controlled by solenoid valve as it is using pneumatic system. A sensor will detect when the metal chip are fully compacted thus sends a signal to the dropping mechanism. The dropping mechanism will drop the compacted metal chip into the storage container thus the final processed product are obtained. Fig. 3 shows the function structure for the portable metal chip baler.



Fig. 2. Function structure black box for a portable metal chip baler.

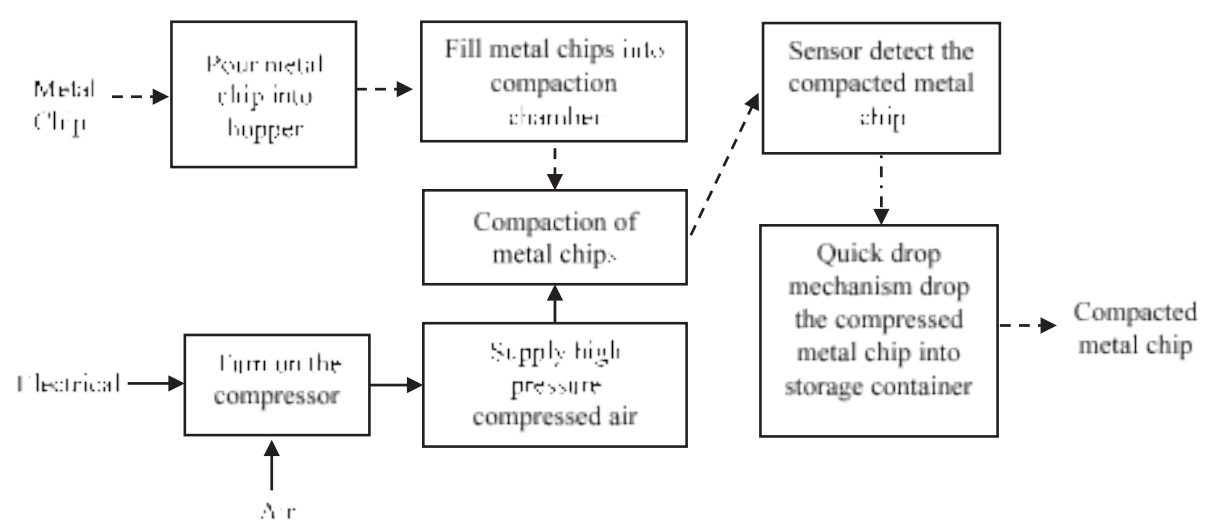

Fig. 3. Function structure for a portable metal chip baler. 


\subsection{Preliminary System Design}

Due to achieve that solution, a new or modifying an existing product is designed based on concept generation and interpreting ideas that are obtained from the previous phase. In this study, the method of generating concepts is using morphological chart method. The morphological chart encourages the designers to widen the search of possible new solution regarding to the present problem, to identify the combination and elements or components that can be implemented to the design concept [6].

Table 1 shows the morphological chart for portable metal chip baler system that has been structured to search several possible combinations. For the complete combinations, eight sub-systems have been combined where only one alternative for each sub-system will be selected. Fig. 4 shows the three combinations that have been structured based on the morphological analysis.

After generated with several combinations, an evaluation is needed to select the best combination. The evaluation can be done by considering the objectives that the design supposed to be achieved. The tool that has been used to evaluate the combinations is weighted rating method that is carried out by comparing the selected alternative design and evaluated using rating scales 0 to 5 where the highest rating is better. Then the assigned rating is multiplied with the importance factor and the total points are summed up and the weightage of each features or specs are obtained.

Table 1. Morphological Chart for Portable Metal Chip Baler System

\begin{tabular}{|c|c|c|c|c|}
\hline \multirow{2}{*}{ No } & \multirow{2}{*}{ Sub-system } & \multicolumn{3}{|c|}{ Alternatives } \\
\hline & & 1 & 2 & 3 \\
\hline 1 & Power Source & Electricity & Petrol Engine & Solar \\
\hline 2 & $\begin{array}{l}\text { Metal Chip Detection } \\
\text { Mechanism }\end{array}$ & Touch Sensor & Distance Sensor & Infrared Sensor \\
\hline 3 & Control System & $\begin{array}{c}\text { Pneumatic Control } \\
\text { Valve }\end{array}$ & Solenoid Valve & Electric Switch \\
\hline 4 & Air Supply & Piston System & Air Supply Device & Compressor \\
\hline 5 & Vibration Insulator & Rubber & Insulation Pad & Spring \\
\hline 6 & Portability & $\begin{array}{l}3 \text { inch Caster } \\
\text { Wheel }\end{array}$ & 5 inch Caster Wheel & 7 inch Caster Wheel \\
\hline 7 & $\begin{array}{c}\text { Metal Chip Compaction } \\
\text { Mechanism }\end{array}$ & Hydraulic & $\begin{array}{c}\text { Flat plate with } \\
\text { pneumatic cylinder }\end{array}$ & Motorized \\
\hline 8 & Product Material & Aluminium & Stainless Steel & Galvanized Steel \\
\hline
\end{tabular}




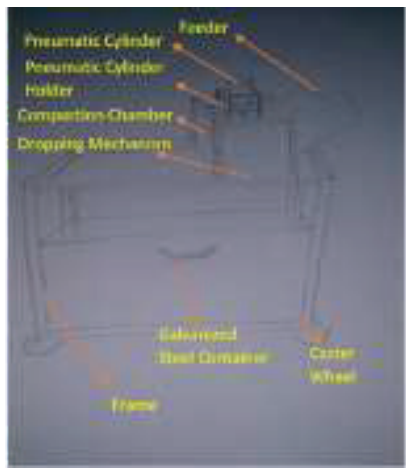

(a) Concept 1



(b) Concept 2

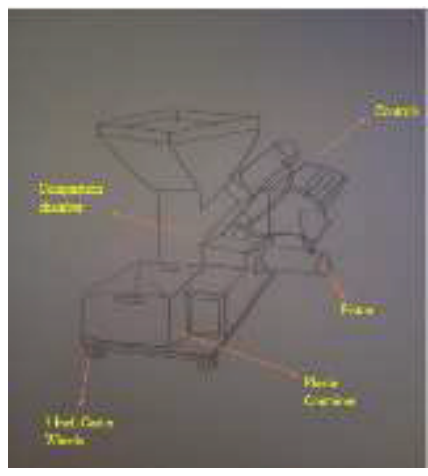

(c) Concept 3

Fig. 4. Sketches of Portable Metal Chip Baler concepts.

Table 2 shows the weighted rating method for evaluating the combinations of portable metal chip baler. For the evaluation, a set of 12 criteria that was based on the design objectives has been considered. Based on the evaluation, combination 1 has the highest total score among the other combinations. It is believed, the combination 1 has the highest score due to the simplest design, low maintenance cost as the spare parts are cheap and portable. However, the dimension has an average score. The safety and green friendly aspects of each alternative is equal among the alternatives.

Table 2. Weighted rating method for Portable Metal Chip Baler

\begin{tabular}{|c|c|c|c|c|c|c|c|}
\hline \multirow{3}{*}{ Design Criterion } & \multirow{3}{*}{$\begin{array}{l}\text { Weight } \\
\text { Factor }\end{array}$} & \multicolumn{6}{|c|}{ Concepts } \\
\hline & & \multicolumn{2}{|c|}{1} & \multicolumn{2}{|c|}{2} & \multicolumn{2}{|c|}{3} \\
\hline & & $\mathbf{R}$ & W & $\mathbf{R}$ & W & $\mathbf{R}$ & W \\
\hline Interesting Design & 0.16 & 4 & 0.64 & 3 & 0.48 & 2 & 0.32 \\
\hline Machine cost & 0.14 & 3 & 0.42 & 2 & 0.28 & 3 & 0.42 \\
\hline Spare parts price & 0.02 & 3 & 0.06 & 1 & 0.02 & 2 & 0.06 \\
\hline Labour cost & 0.04 & 4 & 0.16 & 3 & 0.12 & 3 & 0.12 \\
\hline Easy to use & 0.04 & 4 & 0.16 & 3 & 0.12 & 2 & 0.08 \\
\hline Number of operator & 0.03 & 4 & 0.12 & 2 & 0.06 & 3 & 0.09 \\
\hline Portable & 0.04 & 3 & 0.12 & 2 & 0.08 & 3 & 0.12 \\
\hline Size & 0.06 & 3 & 0.18 & 3 & 0.18 & 4 & 0.24 \\
\hline Weight & 0.05 & 3 & 0.15 & 2 & 0.10 & 3 & 0.15 \\
\hline Low maintenance cost & 0.14 & 3 & 0.42 & 2 & 0.28 & 2 & 0.28 \\
\hline Safety & 0.17 & 4 & 0.68 & 4 & 0.68 & 4 & 0.68 \\
\hline Green friendly & 0.11 & 4 & 0.44 & 3 & 0.33 & 4 & 0.44 \\
\hline Total & & & 3.49 & & 2.55 & & 3 \\
\hline
\end{tabular}

* $\mathrm{R}=$ Rating; $\mathrm{W}=$ Weightage 
Table 3 shows the sub-systems and the selected components with the function that they are required to perform on the portable metal chip baler. In this study, the power supply that suits for this product is from electricity because it is easy to obtain and it does not product any greenhouse effect as this study is to reduce metal waste. For the metal chip detection function, a touch sensor is chosen to be used as it more effective as when the plate that compacts the metal chip touches the sensor. It will operate the dropping mechanism so the compacted metal chip will fall into the container.

Table 3. Assigned functions for Portable Metal Chip Baler System.

\begin{tabular}{|c|c|c|}
\hline Sub-system & Component & Function \\
\hline Power Source & Electricity & Act as a power source for the project \\
\hline $\begin{array}{l}\text { Metal Chip } \\
\text { Detector }\end{array}$ & Touch Sensor & $\begin{array}{l}\text { To detect the metal chip after compaction } \\
\text { process }\end{array}$ \\
\hline Control system & Solenoid Valve & To control the pneumatic system \\
\hline Air Supply & Air Compressor & To generate and store air pressure. \\
\hline Vibration & Rubber Absorber & $\begin{array}{l}\text { To absorb vibration from the compaction } \\
\text { process }\end{array}$ \\
\hline Portable & Caster Wheel & To support and make the project portable \\
\hline $\begin{array}{l}\text { Metal Chip } \\
\text { Compaction } \\
\text { Mechanism }\end{array}$ & $\begin{array}{c}\text { Flat plate with } \\
\text { pneumatic cylinder }\end{array}$ & $\begin{array}{l}\text { Used to compact the metal chip in the } \\
\text { compaction chamber }\end{array}$ \\
\hline Storage & Metal Container & $\begin{array}{l}\text { To store the metal chip that has been } \\
\text { compacted. }\end{array}$ \\
\hline
\end{tabular}

Pneumatic system using solenoid valve is used to control the air flowing into the cylinder thus control the compaction mechanism. Air compressor is used to generate air pressure and store it into a storage tank before it is used to compact the metal chip. The product may produces vibration as it compacts the metal chip so rubber insulator is selected to reduce the vibration from the product to the floor surface. Caster wheels are selected to be used due to its availability as it is easy to find. The storage container will be made from galvanized steel because it is much stronger ad cheaper thus it is suitable to get the job done.

\subsection{Detail Design and Development}

In this section, the proposed design concept of a portable metal chip baler is modelled using SolidWorks software. In order to assemble a complete 3D CAD model of the portable metal chip baler (as shown in Fig. 5a), all components that has been identified in the previous phase have been drawn in the first step. After complete in the design stage, the proposed design of portable metal chip baler (as shown in Fig. 5b) is fabricated for prototype testing in the next phase. 


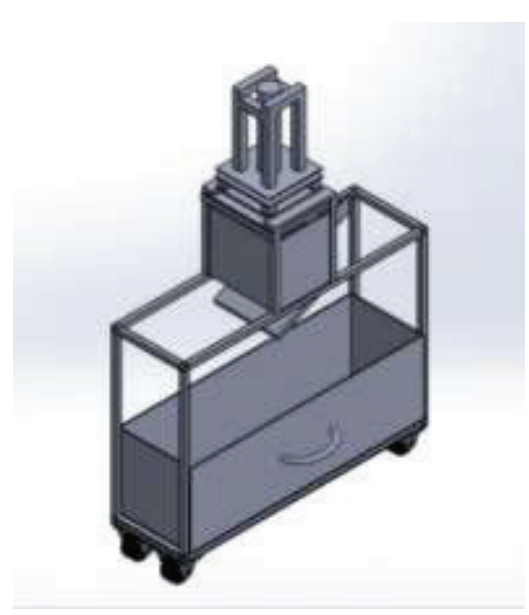

(a) 3D CAD model.

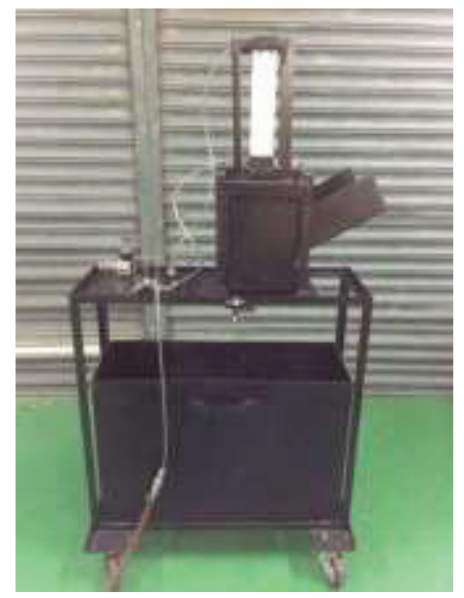

(b) Prototype development.

Fig. 5. Design and development of Portable Metal Chip Baler.

\subsection{System Test and Evaluation}

After the portable metal chip baler is fabricated, prototype testing is conducted in order to verify whether the design system satisfies the objective of this study or not. During the prototype testing, a pile of metal chip is gathered and feed into the portable metal chip baler and the compacting process is carried out. The testing is conducted three times to ensure the result is satisfied. Fig. 6 shows the process of testing from a barrel of metal chips in a workshop and compaction process using the prototype to several compacted metal chips.

From the testing, the prototype successfully compact the metal chip into a compact square block shape thus reducing the initial size of the metal chips. The prototype had been succeeded and the objective of this study has been achieved.

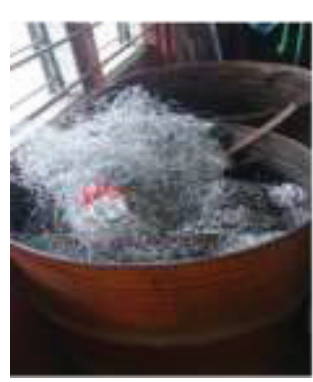

(a) Metal chips ;
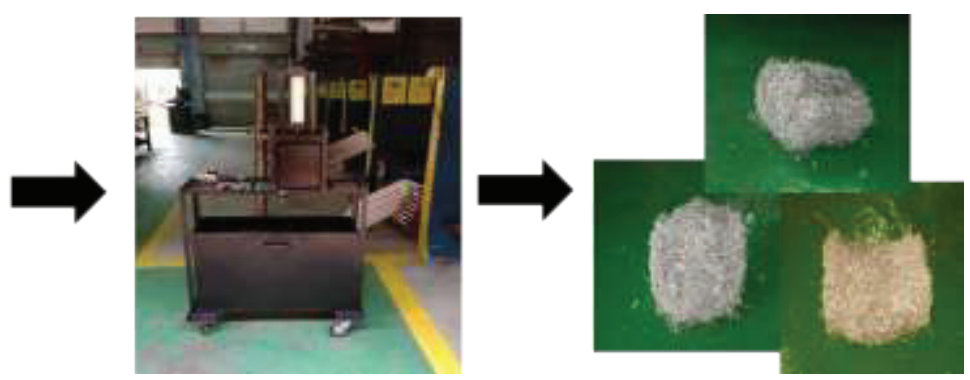

(b) Developed metal chip baler ; (c) Several compacted metal chips

Fig. 6. Prototype testing

\section{Conclusion}

In conclusion, a portable metal chip baler that can compact metal chips using a system design approach is presented. Based on the system design approach, several phases have 
been performed in order to fulfil the required objectives. The phases include conceptual design, preliminary system design, detail design and development, and system test and evaluation. The process is started from the conceptual design where the function analysis is performed. This phase identified the important system that should be implemented to support the portable metal chip baler. In this phase, the input and output of the system, also the detail system inside of the black box are determined. Then, in the preliminary system design, the process is continued with generating three possible alternatives using morphological chart, evaluating the generated combinations using weighted rating method, and selection process where combination 1 is preferred concept since the score obtained is higher than the others with regard to the assigned criteria. Next, the 3D CAD model of the proposed concept for the portable metal chip baler is designed and fabricated for prototype testing as suggested in the detail design and development phase. In the last phase, the developed prototype has been tested three times for verification purpose. This testing has been conducted for proof-of-concept test so that the proposed concept of portable metal chip baler is working as suggested. The output from this prototype is compacted metal chips where the result means the successful of this study. This result is a preliminary work where further improvement will be made for better result. At the end of this study, the portable metal chip baler can be used by industries for proper metal waste management.

\section{Acknowledgement}

This research was funded by Universiti Tun Hussein Onn Malaysia (UTHM) under Incentive Grant Scheme for Publication (IGSP) with Vot no. U411.

\section{References}

1. G. Esenduran, E. Kemahlioglu-Ziya, J.M. Swaminathan, Product Take Back Legislation and Its Impact on Recycling and Remanufacturing Industries. In Sustainable Supply Chains. (Springer, New York, 2012).

2. Skanska, 4R Guide: Reduce, Reuse, Recycle, Recover. (Stockholm: Skanska Group, 2012).

3. L. Simon, C.A.M. Moraes, R.C.E. Modolo, M. Vargas, D. Calheiro, F.A. Brehm, Journal of Cleaner Production, 153 (2017).

4. L. Wzorek, M. Wedrychowicz, T. Skrzekut, P. Noga, M. Wiewiora, J. Wiewiora, W. Sajdak, M. Richert, Metallurgy and Foundry Engineering, 42, 2 (2016).

5. K.B. Misra, Engineering Design: A Systems Approach. In Handbook of Performability Engineering. (Springer, London, 2008).

6. M.F. Hassan, M.Z.M. Saman, S. Sharif, B. Omar, Int. J. Sustainable Manufacturing, 2, 4 (2012).

7. M.F. Hassan, M.K. Keat, M.Z. Yunos, S. Adzila, A.M.T. Arifin, M.N.A. Rahman, R.H.A. Haq, ARPN Journal of Engineering and Applied Sciences, 11, 12 (2016). 